\title{
衝撃引張りにおける粘弾性的挙動
}

\begin{tabular}{|c|c|c|c|}
\hline 名古屋市工業研究所 & 中 & 島 & 達 \\
\hline $1 "$ & 堺 & & 泰 \\
\hline
\end{tabular}

\section{A Study on the Visco-Elastic Behavior of Filament which Undergoes Impulsive Tension at the End.}

\author{
Tatsuo Nakashima and Yasuo Sakai, \\ Nagoya Municipal Industrial Research Institute, Nagoya City.
}

\section{1. 緒言}

衝撃に対する材料の挙動は各種の要因が複合されるう えに測定が困難なためまだ充分解決されているとはいえ ない現状であり，特に紴維形成質の衝撃引張りに関する 力学的研究は少ないようである. 弾塑性体の引張りにつ (ては Von Kàrmàn ${ }^{1)}$ や Rakuhmatulinら2) によって 解析されているが，そてでは粘性的考慮は払われていな い. 高分子材料あ衝撃挙動としては弾性的な性質が強く 表に現われるので, 弾塑性的理論でも充分近似適用可能 であるが, 衛撃現象に扔いてもクリープや応力緩和がみ られるととは幾多の実験で示されており 粘弾性的解析が必要となってくる. J. A. Morrison ${ }^{4)}$ は Voigt モデルおよび三要素モデルで示される粘弾性棒に おける衝撃波の伝播について数学的解析をしているがそ の結果は糸の場合にも参考となる点が多い.

ところで本稿では主に数值解析的立場に立ち, 静止中 の糸の一端に一定速度を衝撃的に与えた場合に示す系の 挙動, すなわち各部の歪み, 張力, 移動速度等を調べる のを目的として, Laplace 変換を用いる近似解法を試み るととあに, それらの数值結果を特性曲線法, 直接差分 近似法による数值解と比較検討してみるてとにする.

\section{2. 力学モデルと基本方程式}

静止している糸の一端を瞬間的に引張る場合糸の示す 挙動を調べる. 糸は無拘束で直線状のまま静止している あのとする. その先端を原点 $x=0$ とし, 長さ方向に $x$ の正軸をとる. 糸は時刻 $t<0$ で 静止を保ち, $t \geqq 0$ K

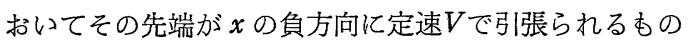
とする. したがって $t=0$ において糸の先端は瞬間的に
ステップ状に速度 $V$ を得ることになる，糸の長さは一応 無限長とする.

糸を粘弾性体とみなし，その力学モデルとして図 1 の

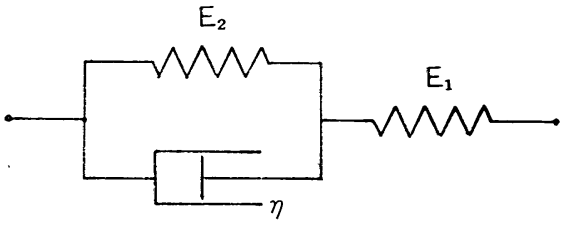

図1 力学モデル

3 要素モデルを想定する。

$E_{1}, E_{2}$, を弾性要素の弾性係数, $\eta$ を粘性要素の粘性 係数之する, 系の $x$ 点に打ける時刻 $t$ の張力を $T(x, t)$, 変位を $u(x, t)$, 歪みを $\varepsilon(x, t)$ であらわす Lagrange 座 標を用いる。

このモデルの満足すべき微分方程式は次式で与えられ る.

$\left(E_{1}+E_{2}\right) T+\eta \partial T / \partial t=\eta E_{1} \partial \varepsilon / \partial t+E_{1} E_{2} \varepsilon$

さらに次のニュートンの第 2 法則をも満足しなくては ならない.

$\rho \partial^{2} u / \partial t^{2}=\partial T / \partial x$

ここで

な招歪と変位の間には次の関係が成立つ.

$\varepsilon=\partial u / \partial x$

そこでての 3 式を合わせて次の微分方程式が得られ る.

$$
\begin{aligned}
& \rho \eta \partial^{3} u / \partial t^{3}+\rho\left(E_{1}+E_{2}\right) \partial^{2} u / \partial t^{2} \\
& \quad-\eta E_{1} \partial^{3} u / \partial t \partial x^{2}-E_{1} E_{2} \partial^{2} u / \partial x^{2}=0
\end{aligned}
$$


初期条件拉よび境界条件は

$u(x,+0)=0,(\partial / \partial t) u(x,+0)=0$,

$\left(\partial^{2} / \partial t^{2}\right) u(x,+0)=0 \quad(x>0)$

$u(+0, t)=-V t, u(\infty, t)=0 \quad(t>0)$

次に上の微分方程式を無次元化するため

$E_{1} / E_{2}=\alpha, \eta / E_{2}=\tau_{0}, \sqrt{E_{1} / \rho}=c$

$x /\left(c \tau_{0}\right)=\xi, t / \tau_{0}=\tau, V / c=\varphi$

$u(x, t) /\left(c \tau_{0}\right)=U(\xi, \tau)$

とおけば(4)式は

$\partial^{3} U / \partial \tau^{3}+(1+\alpha) \partial^{2} U / \partial \tau^{2}-\partial^{3} U /\left(\partial \tau \xi^{2}\right)-\partial^{2} U / \partial \xi^{2}$

$=0$.

$U(\xi,+0)=0, \quad U_{\tau}(\xi,+0)=0$

$U_{\tau \tau}(\xi,+0)=0 \quad(\xi>0)$

$U(+0, \tau)=-\varphi \tau, U(\infty, \tau)=0 \quad(\tau>0)$

ここで $U_{\tau}=\partial U / \partial \tau, U_{\tau \tau}=\partial^{2} U / \partial \tau^{2}$ を示す.

乙の微分方程式を解けば糸の挙動が知られる. 以下を の解法を 2,3 試みる.

\section{3. 基本方程式の解法}

微分方程式 $(6)$ 6について $L_{+}$変換し，そのラプラ ス变数を $s$ とすると.

$(s+1) \widetilde{U}_{\hat{\xi} \xi}(\xi, s)-s^{2}(s+1+\alpha) \widetilde{U}(\xi, s)=0$

ただし $\widetilde{U}(\xi, s)=\int_{+0}^{\infty} e^{-s \tau} \dot{U}(\xi, \tau) d \tau$

$\xi \rightarrow \infty$ において $U(\xi, \tau)=0$ であるから

$\widetilde{U}(\infty, s)=0$, また $\widetilde{U}(+0, s)=L_{+}[-\varphi \tau]=-\varphi / s^{2}$.

したがって（7）式から次の解が得られる.

$$
\widetilde{U}(\xi, s)=-\varphi / s^{2} \exp [-s \sqrt{(s+1+\alpha) /(s+1)} \xi]
$$

各部の変位 $U(\xi, \tau)$ は上式を $s$ につて逆変換すれば 得られる.

\section{1 引張端部の歪みと張力}

上記の結果より,まず引張端部に抢ける歪みと張力の 状態を調べてみよう. 先端部の歪み $\varepsilon(0, \tau)$ は $(8)$ 式よ り次のように得られる.すなわち( 8 )式より.

$$
\widetilde{U}_{\xi}(0, s)=\varphi / s \cdot \sqrt{(s+1+\alpha) /(s+1)} \cdot .
$$

乙れを逆変換すると先端部の歪み $\varepsilon(0, \tau)$ すなわち $U_{\xi}$ $(0, \tau)$ が次のように得られる.

$$
U_{\xi}(0, \tau)=\varphi\left[\exp (-(1+\alpha / 2) \tau) I_{0}(\alpha \tau / 2)+(1+\alpha)\right.
$$

$\left.\int_{0}^{\tau} \exp (-(1+\alpha / 2) y) I_{0}(\alpha y / 2) d y\right]$

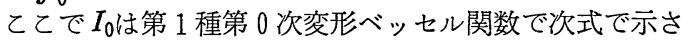
れるものである.

$$
I_{0}(z)=\sum_{n=0}^{\infty}(z / 2)^{2 n} /(n !)^{2}
$$

また引張端部の張力 $T(0, \tau)$ は次のようにして求めら れる.

(1) 式を（5）式を用いて無次元化すると

$(1+\alpha) T / E_{1}+1 / E_{1} \cdot \partial T / \partial \tau=\partial \varepsilon / \partial \tau+$

したがって

$$
L[T] / E_{1}=\frac{s+1}{s+1+\alpha} \quad L[\varepsilon]
$$

故比

$$
\begin{aligned}
& T(0, \tau) /\left(\varphi E_{1}\right)=L^{-1}\left[\frac{1}{s} \sqrt{\frac{s+1}{s+1+\alpha}}\right] \ldots \ldots \\
& =\exp (-(1+\alpha / 2) \tau) I_{0}(\alpha \tau / 2) \\
& \left.\quad+\int_{0}^{\tau} \exp (-(1+\alpha / 2) y) I_{0}(\alpha y / 2) d y\right)
\end{aligned}
$$

以上の結果より先端部の㞘みおよび張力の初期值と漸 近值をまず求めてみよう．漸近法則を用い，(9)，(14） 式より

$$
\begin{aligned}
& \lim _{\tau \rightarrow 0} \varepsilon(0, \tau)=\lim _{\tau \rightarrow 0} U_{\xi}(0, \tau)=\lim _{s \rightarrow \infty} s \widetilde{U}_{\xi}(0, s)=\varphi \\
& \lim _{\tau \rightarrow \infty} \tau(0, \tau)=\lim _{\tau \rightarrow \infty} U_{\hat{\xi}}(0, \tau)=\lim _{s \rightarrow 0} s \widetilde{U}_{\xi}(0, s)= \\
& \varphi \sqrt{1+\alpha} \\
& \lim _{\tau \rightarrow 0} T(0, \tau)=\lim _{s \rightarrow \infty} s L\{T(0, \tau)]=\varphi E_{1} \\
& \lim _{\tau \rightarrow \infty} T(0, \tau)=\lim _{s \rightarrow 0} s L[T(0, \tau)]=\varphi E_{1} / \sqrt{1+\alpha}
\end{aligned}
$$

すなわち先端部の歪みは初期值が $\varphi$ で時刻の径過とと 屯に濞増し $\varphi \sqrt{1+\alpha}$ 亿漸近する。一方張力は初期值 $\varphi E_{1}$ で次第に漸減し $\varphi E_{1} / \sqrt{1+\alpha}$ に漸近する.

また任意の時刻化抬ける先端部の歪みと張力は (10), (16)式から知られるが，いま $\alpha \tau$ があまり大きくない範 囲を対象とするてととして近似解を求めてみよう. 関数 $I_{0}$ の第 2 頂までをとり (10)，(16)式を解くと

$$
\begin{aligned}
\varepsilon(0, \tau)= & \frac{\varphi}{8(1+\alpha / 2)^{3}}\left[(1+\alpha)\left(8+8 \alpha+3 \alpha^{2}\right)\right. \\
& -\exp (-(1+\alpha / 2) \tau)\left\{\alpha\left(4+5 \alpha+2 \alpha^{2}\right)\right. \\
& \left.\left.+\alpha^{2}(1+\alpha)(1+\alpha / 2) \tau+\frac{1}{4} \alpha^{3}(1+\alpha / 2)^{2} \tau^{2}\right\}\right]
\end{aligned}
$$

$$
\begin{array}{r}
T(0, \tau) \fallingdotseq \varphi E_{1}\left[\frac{8+8 \alpha+3 \alpha^{2}}{8(1+\alpha / 2)^{3}}+\left\{\frac{(4+3 \alpha+\alpha}{8(1+\alpha / 2)}\right.\right. \\
\left.-\frac{\alpha^{2}}{8(1+\alpha / 2)^{2}} \tau+\frac{\alpha^{3}}{32(1+\alpha / 2)} \tau^{2}\right\} \\
\quad \quad \quad \quad \quad x p(-(1+\alpha / 2) \tau)] \cdots \cdots \cdots . . .
\end{array}
$$

3.2 各部の変位 $U(\xi, \tau)$

つぎに各部分の変位 $U(\xi, \tau)$ を調べる．乙の変位の像 関数は（8）式で示されるので, これを逆変換すればよ い. 乙の逆変換は相当面倒であるが J.A. Morrison によ って巧み導びかれている. しかしその結果はあまり簡 明な形ではないので，乙てでは近似解を求めてみる.

(8)式より

$$
\begin{aligned}
\widetilde{U}(\xi, s)= & -\frac{\varphi}{s^{2}} \exp \left[-s \sqrt{\frac{s+1+\alpha}{s+1}} \xi\right] \\
& =-\frac{\varphi}{s^{2}} \exp \left[-\sqrt{s^{2}+\alpha s-\alpha+\alpha /(s+1)} \xi\right] \\
& =-\frac{\varphi}{s^{2}} \exp \left[-\sqrt{s^{2}+\alpha s-\alpha} \xi\right]+\beta \cdots(20)
\end{aligned}
$$

$\alpha \tau$ があまり大きくない範囲では $\beta$ の值は小さいものと考 えられる. 上式の右辺の第 1 頂の逆変換は次のように容 易汇得られる。 


$$
\begin{aligned}
& L^{-1}\left[\exp \left(-\sqrt{s^{2}+\alpha s-\alpha} \xi\right)\right] \\
& =\exp (-\alpha \xi / 2) L^{-1}[\exp (-\xi s)] \\
& +\sqrt{\alpha+\alpha^{2} / 4} \xi \exp (-\alpha \tau / 2) I_{1}\left(\sqrt{\alpha+\alpha^{2} / 4}\right. \\
& \left.\quad \sqrt{\tau^{2}-\xi^{2}}\right) / \sqrt{\tau^{2}-\xi^{2}}
\end{aligned}
$$

したがって合成積分より

$$
\begin{aligned}
& U(\xi, \tau) /-\varphi)=(\tau-\xi) \exp (-\alpha \xi / 2) \\
& +\sqrt{\alpha+\alpha^{2} / 4} \xi \int_{\xi}^{\tau}(\tau-\xi) \exp (-\alpha \tau / 2) I_{1} \\
& \quad\left\{\sqrt{\alpha+\alpha^{2} / 4} \sqrt{\tau^{2}-\xi^{2}}\right\} / \sqrt{\tau^{2}-\xi^{2}} d \tau \ldots .
\end{aligned}
$$

ここで $I_{1}$ は第 1 種第 1 次变形ベッセル関数で,

$I_{1}(z)=\sum_{n=0}^{\infty}(z / 2)^{2 n+1} /\{n !(n+1) !\}$

で示されるあのである.いまその第 2 頂までをとって (21)式を計算すると

$$
\begin{aligned}
& U(\xi, \tau) /(-\varphi) \fallingdotseq\left[\tau-\xi+(1+\alpha / 4) \xi\left\{\frac{12+7 \alpha}{2 \alpha^{2}}\right.\right. \\
& \left.\left.+\frac{2(1+\alpha / 4)}{\alpha} \xi\right\}\right] \exp (-\alpha \xi / 2)-(1+\alpha / 4) \xi \\
& {\left[\frac{12+7 \alpha}{2 \alpha^{2}}+\frac{12+7 \alpha}{4 \alpha} \tau+\frac{3}{4}(1+\alpha / 4) \tau^{2}+\frac{\alpha}{8}(1+\alpha / 4) \tau^{3}\right.} \\
& -\left(\frac{4+5 \alpha}{4 \alpha}+\frac{1+\alpha / 4}{2} \tau+\frac{\alpha(1+\alpha / 4)}{8} \tau^{2}\right) \xi \\
& \left.-\frac{1+\alpha / 4}{8}(2+\alpha \tau) \xi^{2}+\frac{\alpha(1+\alpha / 4)}{8} \xi^{3}\right] \exp (-\alpha \tau / 2)
\end{aligned}
$$

上式により各部の変位を近似的に計算することができ る.また各部の歪みは変位の微分より次のように得られ る.

$$
\begin{aligned}
& \varepsilon(\xi, \tau) / \varphi \fallingdotseq\left[1-\frac{(1+\alpha / 4)(6+7 \alpha / 2)}{\alpha^{2}}+\frac{\alpha}{2} \tau\right. \\
& \left.-\frac{2-\alpha+5 \alpha^{2} / 8}{2 \alpha} \xi+(1+\alpha / 4)^{2} \xi^{2}\right\rfloor \exp (-\alpha \xi / 2) \\
& +(1+\alpha / 4)\left[\frac{12+7 \alpha}{2 \alpha^{2}}+\frac{12+7 \alpha}{4 \alpha} \tau+\frac{3(1+\alpha / 4)}{4} \tau^{2}\right. \\
& +\frac{\alpha(1+\alpha / 4)}{8} \tau^{3}-\left\{\frac{4+5 \alpha}{2 \alpha}+(1+\alpha / 4) \tau\right. \\
& \left.+\frac{\alpha(1+\alpha / 4)}{4} \tau^{2}\right\} \xi-\frac{3(1+\alpha / 4)(2+\alpha \tau)}{8} \xi^{2} \\
& \left.+\frac{\alpha(1+\alpha / 4)}{2} \xi^{3}\right] \exp (-\alpha \tau / 2) \cdots \cdots \cdots \cdots \cdots \cdots \cdots \cdots \cdots \cdots \cdots \cdots
\end{aligned}
$$

\section{4. 数值計算例}

衝撃引張りを受ける糸の挙動に関する近似解法を導び いたが, 以下ではそれらの数值計算例の 結果を若干示 す. 計算はコンピュータ FACOM 230 - 60kよった. た だし(18)，(19)，両式の計算は筆算による.

比較に用いた特性曲線法之直接差分近似法の概要は次 の通りである.

(i) 特性曲線法

$\bar{\varepsilon}=\varepsilon /(V / c), \bar{T}=(T / E) /(V / c), \bar{v}=v / V$ 之無次元 化し, $(v=\partial u / \partial t$, 分子の移動速度) (1), (2)，(3)の 連立微分方程式を用い, 次の 6 個の式が得られる。

$$
\left(\begin{array}{rrrrrr}
-1 & 0 & 1 & 0 & 0 & 0 \\
0 & 1 & 0 & 0 & -1 & 0 \\
0 & 0 & 1 & 0 & 0 & -1 \\
d \tau & d \xi & 0 & 0 & 0 & 0 \\
0 & 0 & d \tau & d \xi & 0 & 0 \\
0 & 0 & 0 & 0 & d \tau & d \xi
\end{array}\right)\left(\begin{array}{l}
\partial \bar{T} / \partial \tau \\
\partial \bar{T} / \partial \xi \\
\overline{\bar{\varepsilon}} / \partial \tau \\
\overline{\bar{\varepsilon} / \partial \xi} \\
\overline{\bar{v}} / \partial \tau \\
\overline{\partial \bar{v} / \partial \xi}
\end{array}\right)-\left(\begin{array}{c}
a \bar{T}-\bar{\varepsilon} \\
0 \\
0 \\
d \bar{T} \\
d \bar{\varepsilon} \\
d \bar{v}
\end{array}\right)
$$

但し $a=1+\alpha$

てれより特性曲線（3 本の直線）と，その線上で满足 される微分関係式が次のように得られる.

特性曲線 微分関係式

$$
\begin{array}{cc}
d \xi / d \tau=1 & d \bar{v}-d \bar{T}=(a \bar{T}-\bar{\varepsilon}) d \xi \\
d \tau / d \xi=-1 & d \bar{v}+d \bar{T}=(a \bar{T}-\bar{\varepsilon}) d \xi \\
d \xi=0 & d \bar{\varepsilon}-d \bar{T}=(a \bar{T}-\bar{\varepsilon}) d \tau
\end{array}
$$

$\tau, \xi$ きざみを等しくhにとり, $\tau=0, \tau=-h$ にお いて $\bar{V}=\bar{T}=\bar{\varepsilon}=0(\xi>0)$ を出発点として, 順次 $\tau$ の正方向に逐次節点の值を計算してゆけばよい. 試料が 自由端をむつ有限長の場合にはその自由端で $\bar{T}=0$ とな るととを考慮する。

(ii) 直接差分法

$\xi, \tau$ 方向の きざみを等しく $h$ にとり $U_{i},{ }_{j} \equiv U(\xi=$ $h, \tau=j h)$ として基本方程式（6）より

$\left(U_{i, j+1}-3 U_{i, j}+3 U_{i, j-1}-U_{i, j-2}\right)+(1+\alpha)\left(U_{i, j+1}\right.$ $\left.-2 U_{i, j}+U_{i, j-1}\right) h-\left[\left(U_{i+1, j}-2 U_{i, j}+U_{i-1, j}\right)-\right.$ $\left.\left(U_{i+1, j-1}-2 U_{i, j-1}+U_{i-1, j-1}\right)\right]-\left(U_{i+1, j}-2 U_{i, j}\right.$ $\left.+U_{i-1, j}\right) h=0$

てれは次のような配置様式で示される。

$$
\left(\begin{array}{ccc}
-1+(1+\alpha) h & \\
1+h & 1+2 \alpha h & 1+h \\
-1 & -1-(1+\alpha) h & -1
\end{array}\right) \quad U_{i, j}=0
$$

初期条件，境界条件は

$$
\begin{aligned}
& U_{i, j}=0 \quad(j \leqq 0), \quad U_{i, j}=0 \quad(i \geqq j) \\
& U_{0, j}=-j h \varphi
\end{aligned}
$$

てれらの条件を用いて 前進的に逐次 $U_{i, j}$ が求められ る. 試料が自由端をすつ有限長の場合には仮想点 $\xi=$ $(2 n+1) h$ を考え， $U_{2 n-1, j}=U_{2 n-1, j}$ として取扱えばよ (2.

\section{1 引端張部の丕と張力}

ラプラス変換法によって得られた解（10）式および （16）式を用いた計算結果を図 2 亿図示する. 歪み, 張 力の変化は両者相反する傾向を示すがともに指数関数的 な変化である，な㹁同法の近似解(18)式打よび(19)式に よる計算結果, さらに特性曲線法による計算結果之の比 較を表 1 亿示す.ここで特性曲線法（3）では きざみ 数は単位長を 40 等分して計算した. 表 2 に見られように 


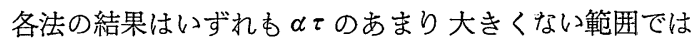
よく近似している.

なお表の $\tau=2.0$ の 3 ）の值が異状を示しているが, 乙れは有限長 $(\xi=1)$ の場合について計算したので反 射波の影響を受けているためである.

\section{2 各部の歪み, 張力, 変位および移動速度}

試料が有限長 $(\xi=1)$ で, 自由端で反射の生ずる場 合の各部の挙動について特性曲線法により得られた計算 例を図 3 亿示す. $\alpha=1$ の場合を示した. 図中に参考の ために $\alpha=0$ の場合をあ示してあるあのがあるが，てれ は完全弾性体の場合に相当する. なお比較のため, 表 2 亿他の方法による計算結果を併記して変位の結果を数值

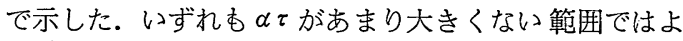
く似た值が得られている.

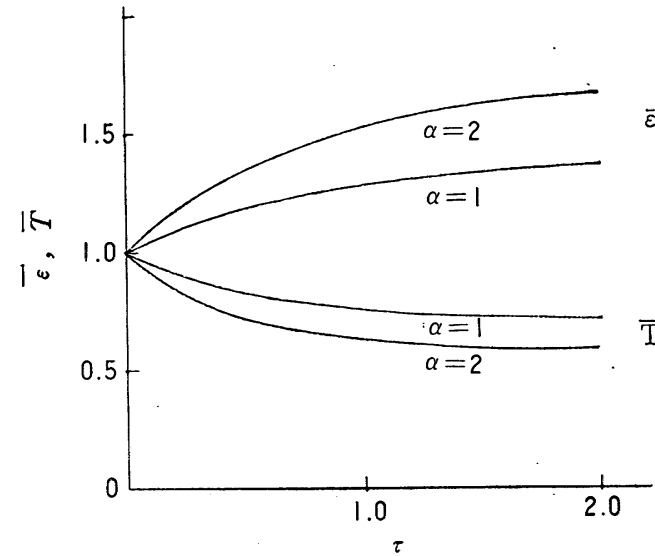

図 2 引張端部の歪み, 張力

表 1 各法による計算結果の比較

1）ラプラス変換法 (10)式，(16)式

2）同近似解 (18)式, (19)式

3) 特性曲線法

a)引張端部における歪み $\bar{\varepsilon}(10, \tau) / \varphi$

\begin{tabular}{|c|c|c|c|c|c|c|}
\hline$\tau$ & 0.0 & 0.4 & 0.8 & 1.2 & 1.6 & 2.0 \\
\hline 1) & 1.000 & 1.158 & 1.254 & 1.314 & 1.351 & 1.369 \\
\hline 2) & 1.000 & 1.158 & 1.254 & 1.313 & 1.350 & 1.372 \\
\hline 3) & 1.000 & 1.158 & 1.254 & 1.314 & 1.351 & - \\
\hline \multicolumn{7}{|c|}{$\alpha=2$} \\
\hline$\tau$ & 0.0 & 0.4 & 0.8 & 1.2 & 1.6 & 2.0 \\
\hline 1) & 1.000 & 1.302 & 1.474 & 1.575 & 1.635 & 1.671 \\
\hline 2) & 1.000 & 1.302 & 1.472 & 1.569 & 1.622 & 1.652 \\
\hline 3) & 1.000 & 1.302 & 1.474 & 1.574 & 1.634 & - \\
\hline
\end{tabular}

（b）引張端部の張力 $\bar{T}(0, \tau) /\left(\varphi E_{1}\right)$

\begin{tabular}{|c|c|c|c|c|c|c|}
\hline$\tau$ & 0.0 & 0.4 & 0.8 & 1.2 & 1.6 & 2.0 \\
\hline 1) & 1.000 & 0.856 & 0.784 & 0.747 & 0.728 & 0.718 \\
\hline 2) & 1.000 & 0.856 & 0.784 & 0.747 & 0.727 & 0.717 \\
\hline 3) & 1.000 & 0.856 & 0.784 & 0.747 & 0.728 & - \\
\hline$\tau$ & 0.0 & 0.4 & 0.8 & 1.2 & 1.6 & 2.0 \\
\hline 1) & 1.000 & 0.746 & 0.648 & 0.609 & 0.592 & 0.585 \\
\hline 2) & 1.000 & 0.746 & 0.647 & 0.605 & 0.583 & 0.575 \\
\hline 3) & 1.000 & 0.746 & 0.648 & 0.609 & 0.592 & - \\
\hline
\end{tabular}




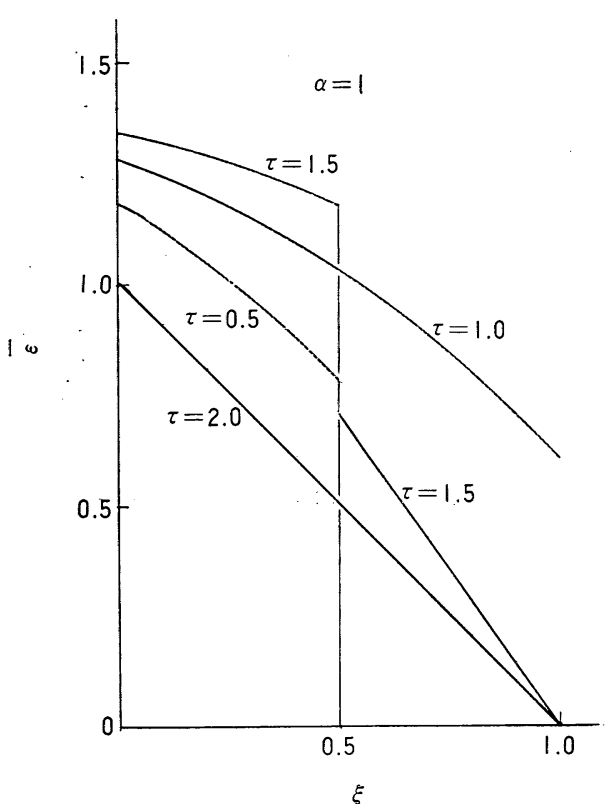

図3 (a) 歪 み $(\alpha=1)$

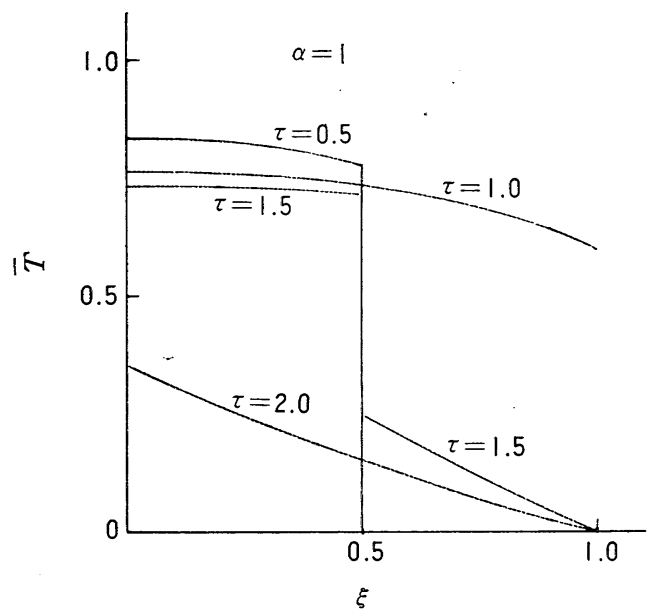

図 3 (b) 張 力

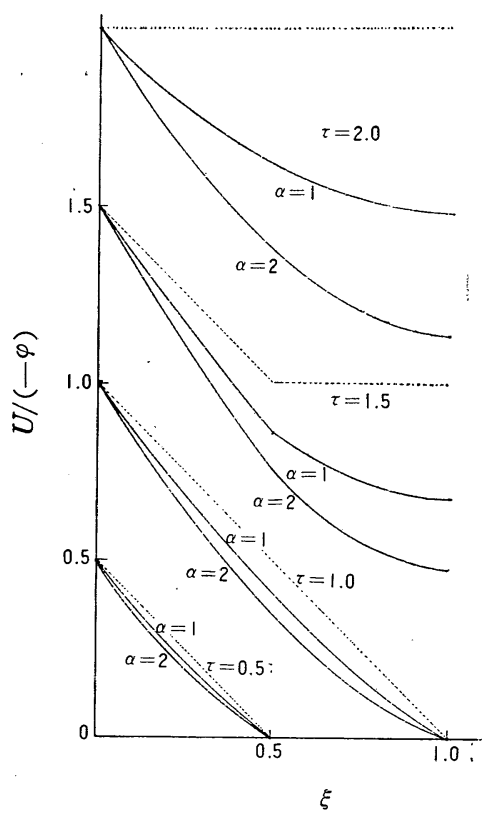

図 3 (c) 变 位

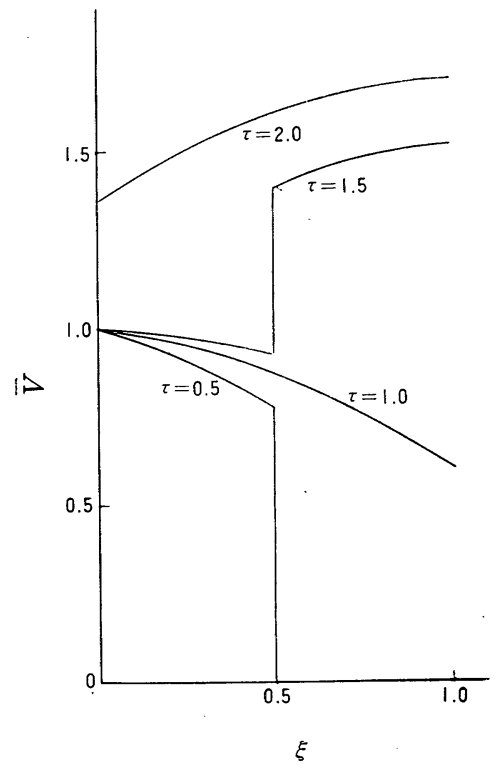

図 3 (d) 移動速度 $(\alpha=1)$

図 3 各部の挙動（試長 1)

表 2 変位 $U(\xi, \tau) /(-\varphi)$ の各法による計算結果の比較

1）ラプラス変換法による近似解（22）式

2）特性曲線法

3) 直接差分法

$\tau=1, \quad \alpha=1$

\begin{tabular}{l|llllll}
\hline \hline $\boldsymbol{\xi}$ & 0.0 & 0.2 & 0.4 & 0.6 & 0.8 & 1.0 \\
\hline 1$)$ & 1.000 & 0.754 & 0.524 & 0.317 & 0.141 & 0.0 \\
$2)$ & 1.000 & 0.751 & 0.521 & 0.316 & 0.140 & 0.0 \\
$3)$ & 1.000 & 0.751 & 0.521 & 0.315 & 0.138 & 0.0 \\
\hline
\end{tabular}




\begin{tabular}{c|llllll}
\multicolumn{2}{l}{$\tau=1, \quad \alpha=2$} & & & & \\
\hline \hline$\xi$ & 0.0 & 0.2 & 0.4 & 0.6 & 0.8 & 1.0 \\
\hline 1$)$ & 1.000 & 0.710 & 0.460 & 0.254 & 0.100 & 0.0 \\
$2)$ & 1.000 & 0.710 & 0.459 & 0.254 & 0.100 & 0.0 \\
$3)$ & 1.000 & 0.710 & 0.458 & 0.252 & 0.097 & 0.0 \\
\hline
\end{tabular}

\section{5. 結 言}

衝撃引張りを受ける糸の粘弾性的挙動に対前る数值解 析的解法を試みた．ラプラス变換による近似方法は特性 曲線を用いる差分近似法, および前進的な直接差分近似 法と実用的な範囲内ではよい近似を示した。な衫本報は 1973年日本䋐維機械学会年次大会において発表したもの をまとめたものである.

\section{参考文献}

1) T.von Kàrmàn, P.Duwez ; J.Appl. Phy., 21 (1950)

2) H. Kolsky ; Stress Wave in Solid (1953)

3) J. H. Smith C. A. Fenstermaker, R. J. Shouse ; Text. Res. J., 33(1963)

4) J. A. Morrison ; Quart. Appl. Math., 14 No. 2 (昭和 49 年 5 月 2 日受理) 